\title{
Effects of Chemotherapy on Serum Lipids in Chinese Postoperative Breast Cancer Patients
}

This article was published in the following Dove Press journal: Cancer Management and Research

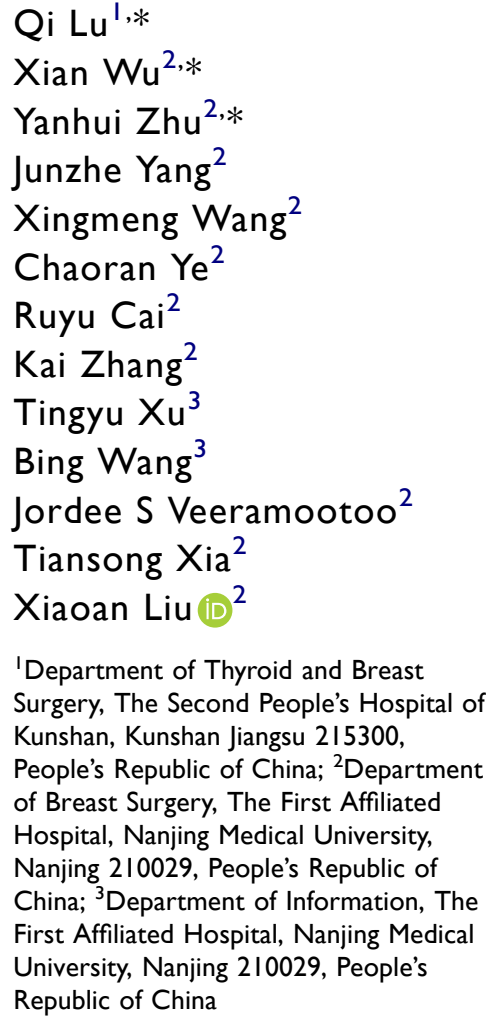

*These authors contributed equally to this work

\begin{abstract}
Purpose: Chemotherapy is a comprehensive therapy for breast cancer; nevertheless, its associated adverse effects are drawing increasing attention with the continuous improvement of the efficacy. The changes in serum lipids of breast cancer patients caused by chemotherapy have been reported by previous studies, whereby the former increase the incidence rate of cardiovascular disorders. However, the variations in the changes of serum lipids with different chemotherapy regimens have seldom been reported.
\end{abstract}

Methods: From January 2011 to December 2017, 1740 breast cancer patients treated with chemotherapy were recruited at the First Affiliated Hospital of Nanjing Medical University. The chemotherapy regimens included anthracycline-based, taxane-based, and anthracyclineplus-taxane-based regimens, dose-dense and standard-interval regimens. Lipid profiles that contained TG (triglyceride), TC (total cholesterol), HDL-C (high-density lipoprotein cholesterol), LDL-C (low-density lipoprotein cholesterol) and Lpa (lipoprotein a) levels were collected prior to the first, second and last cycles of chemotherapy. The changes of serum lipids with the same or different chemotherapy regimens were analyzed and compared.

Results: It was observed that the levels of TG, TC, LDL-C and Lpa increased significantly while that of HDL-C decreased after adjuvant chemotherapy in breast cancer patients $(\mathrm{P}<0.05)$. Besides, dose-dense regimens had more influence in TG and HDL-C and less influence in TC and LDL-C than standard-interval regimens. HDL-C was more sensitive to anthracycline-based regimens than taxane-based regimens. The level of TG with anthracycline-plus-taxane-based regimens was higher than that with only anthracycline-based or taxane-based regimens, and the level of HDL-C with anthracycline-plus-taxane-based regimen showed lower than that with taxane-based regimen.

Conclusion: In summary, this study proposed that dyslipidemia was strongly associated with chemotherapy in Chinese breast cancer patients after operative treatment. Furthermore, the changes in levels of serum lipids varied among patients with different chemotherapy regimens and taxane had less effect on dyslipidemia than anthracycline.

Keywords: breast cancer, serum lipids, dyslipidemia, chemotherapy, treatment

\section{Introduction}

Breast cancer is the most generally diagnosed cancer and also the most common cause of cancer-related deaths in women globally. ${ }^{1-3}$ The mortality rate of breast cancer has decreased dramatically due to the improvements in screening and adjuvant therapies. ${ }^{4}$ Numerous treatments are channeled into improving both disease-free survival (DFS) and overall survival (OS) in breast cancer patients, among which adjuvant chemotherapy plays an important role. ${ }^{5,6}$ With the great progress made in the positive effects of chemotherapy, the side effects gradually receive increasing attention, which may also affect the survival and prognosis of breast cancer patients. ${ }^{7}$
Correspondence: Tiansong Xia; Xiaoan Liu The First Affiliated Hospital, Nanjing Medical University, 300 Guangzhou Road, Nanjing 210029, People's Republic of China Tel/fax +86-25-68308I52

Email liuxiaoan@126.com 
The common side effects of breast cancer chemotherapy include bone marrow suppression, anaphylaxis and gastrointestinal reactions, etc. Meanwhile, cardiac toxicity has also been a long-term problem for patients. ${ }^{8}$ Many studies have indicated that the levels of blood lipid and lipoprotein in breast cancer patients changed during chemotherapy. ${ }^{9,10}$ The unbalanced distribution of lipid and lipoprotein has been proved to be the established risk factor for cardiovascular diseases. ${ }^{11,12}$ Therefore, chemotherapy can promote the occurrence and development of cardiovascular diseases in breast cancer patients by inducing dyslipidemia.

Patients with breast cancer receiving adjuvant chemotherapy had a crucial correlation with cardiovascular disease because dyslipidemia is accompanied by high total cholesterol (TC), triglycerides (TG), low-density lipoprotein cholesterol (LDL-C), lipoprotein a (Lpa) and low high-density lipoprotein cholesterol (HDL-C). Xin et al analyzed the serum lipid levels of 394 breast cancer patients before and after receiving adjuvant chemotherapy, and observed that TC, TG and LDL-C levels of patients after chemotherapy showed significantly higher than those before chemotherapy, and HDL-C levels were significantly lower. ${ }^{13}$ In addition, Grazia et al reported that chemotherapy increased the risk of dyslipidemia in premenopausal and postmenopausal breast cancer patients. ${ }^{14}$

Several studies had revealed that dyslipidemia could be caused by chemotherapy and increased the risks of breast cancer death, recurrence and metastasis. ${ }^{15,16}$ Thus, understanding the potentially detrimental effects of chemotherapy on serum lipid levels is critical to enhance the life quality of breast cancer patients in the future, including the improvement of survival, prognosis and reduction of the incidence of complications. However, few studies have been proceeded on the differences in the changes of serum lipids with different chemotherapy regimens in breast cancer patients. ${ }^{17}$

Therefore, the aim of our study is to investigate the association between serum lipids and chemotherapy in Chinese breast cancer patients, and explore the variations of the changes in different chemotherapy regimens.

\section{Methods}

\section{Patients}

From January 2011 to December 2017, 1740 patients diagnosed with breast cancer were recruited at the First Affiliated Hospital of Nanjing Medical University, Nanjing, Jiangsu, China, which were selected based on the following eligibility criteria: (1) diagnosed as breast cancer by histopathological examination; (2) stage I-III breast cancer; and (3) treated with surgery followed by chemotherapy. The exclusion criteria were listed for: (1) lack of laboratory data; (2) receiving neo-adjuvant therapy; (3) abnormal cardiopulmonary, liver or kidney function; (4) preexisting primary tumors; (5) patients with related diseases affecting serum lipids; (6) taking related drugs that affect serum lipids; (7) male breast cancer patients. All patients provided informed consent for their clinical data to be reviewed by us. This study was approved by the Ethics Committee of the First Affiliated Hospital of Nanjing Medical University and the Helsinki Declaration.

\section{Evaluate Parameters}

This study compares the status of lipids and apolipoproteins in 1740 breast cancer patients at different stages in the chemotherapy process. The laboratory parameters relevant to dyslipidemia TC, TG, HDL-C, LDL-C, and Lpa were recorded before chemotherapy, after the first cycle (equal to before the second cycle) and before the last cycle of chemotherapy. The result report was provided by hematology analyzer Sysmex - 800i (Sysmex Corporation, Kobe, Japan). Dyslipidemia was taken into consideration when one of the followings was observed: $\mathrm{TC} \geqslant 5.2$ $\mathrm{mmol} / \mathrm{L}, \mathrm{TG} \geqslant 1.7 \mathrm{mmol} / \mathrm{L}$, LDL-C $\geqslant 3.4 \mathrm{mmol} / \mathrm{L}$, HDL-C $<1 \mathrm{mmol} / \mathrm{L}$ or non-HDL-C $\geqslant 4.1 \mathrm{mmol} / \mathrm{L}$ according to Guidelines for Prevention and Treatment of Dyslipidemia in Chinese Adults in 2016. This nonrandomized study also collected other clinical information including age, menopausal status, tumor size, nodal stage, histological grade, hormone receptor status, human epidermal growth factor receptor 2 (HER2), Ki67, molecular subtype and weight. The clinical staging adopted TNM (Tumor Node Metastasis) staging of malignant tumors released by the United States Joint Cancer Committee. Pathological information, including estrogen receptor (ER), progesterone receptor (PR), Her-2, and Ki67, were obtained through immunohistochemical (IHC) analysis. Molecular typing was confirmed by the National Comprehensive Cancer Network (NCCN) guidelines.

\section{Treatment}

Adjuvant chemotherapy regimens and dose were determined in accordance with guidelines of the Chinese Society of Clinical Oncology (CSCO) breast cancer, which included: (1) Epirubicin plus Cyclophosphamide (E: $90 \mathrm{mg} / \mathrm{m} 2, \mathrm{C}$ : $600 \mathrm{mg} / \mathrm{m} 2$ ) every 3 weeks for four cycles; (2) Docetaxel 
plus Cyclophosphamide (T: $75 \mathrm{mg} / \mathrm{m} 2, \mathrm{C}: 600 \mathrm{mg} / \mathrm{m} 2$ ) every 3 weeks for four or six cycles; (3) Epirubicin plus Cyclophosphamide (E: $90 \mathrm{mg} / \mathrm{m} 2$, C: $600 \mathrm{mg} / \mathrm{m} 2$ ), followed by paclitaxel (P: $175 \mathrm{mg} / \mathrm{m} 2$ ) every 2 weeks for four cycles; (4) Epirubicin plus Cyclophosphamide (E: $90 \mathrm{mg} / \mathrm{m} 2, \mathrm{C}$ : $600 \mathrm{mg} / \mathrm{m} 2$ ), followed by docetaxel (D: $80 \mathrm{mg} / \mathrm{m} 2$ ) every 3 weeks for four cycles; (5) Docetaxel plus Epirubicin and Cyclophosphamide (T: $75 \mathrm{mg} / \mathrm{m} 2$, E: $90 \mathrm{mg} / \mathrm{m} 2, \mathrm{C}$ : $500 \mathrm{mg} / \mathrm{m} 2$ ) every 3 weeks for six cycles. Additionally, there were some other chemotherapy regimens. It was recommended that patients with Her-2 amplification should receive biological targeted therapy with trastuzumab for a full year.

\section{Statistical Analysis}

The Statistical Package for Social Sciences (SPSS, Inc, Chicago, IL, USA) software version 22.0 was adopted to analyze the data. Mean and standard deviation (SD) were assessed by performing an independent sample $t$-test. Chisquare test was conducted to acquire the predictive factors for dyslipidemia from the clinicopathological factors in the univariate analysis. Multivariate binary logistic regression was channeled into identifying the factors that were independently related to dyslipidemia. Median and comparison of levels of serum lipids and apolipoproteins during the same chemotherapy regimens were determined by using random-effects GLS regression. Two-sample Wilcoxon rank-sum (Mann-Whitney) test was used to compare the levels of serum lipids and apolipoproteins in dose-dense with standard-interval chemotherapy regimens. The levels of serum lipids and apolipoproteins among anthracyclinebased, taxane-based and anthracycline-plus-taxane-based regimens were compared by using Kruskal-Wallis equality-of-populations rank test. $\mathrm{P}<0.05$ was considered to be statistically significant.

\section{Results}

A total of 1740 patients were diagnosed with breast cancer by histopathological examination, which includes 149 patients with EC regimen, 139 patients with TC regimen, 53 with TEC regimen, 534 patients with EC-D regimen and 385 patients with EC-P regimen, and the rest of the patients receiving other chemotherapy regimens. Additionally, 194 patients were treated with Trastuzumab and 32 patients with Capecitabine. The average age of these patients was 48.12 \pm 9.43 years (range, 21-78 years). Nine hundred and sixty-three patients had dyslipidemia before chemotherapy. ER of $67.18 \%$ patients and
HER-2 of $26.55 \%$ patients were positive. The characteristics of patients are shown in Table 1.

The relationship between clinicopathological factors and dyslipidemia before chemotherapy is indicated in Tables 2 and 3. In the univariate analysis, age $(\mathrm{P}<0.05)$, menopausal status $(\mathrm{P}<0.05)$, PR status $(\mathrm{P}<0.05)$ and weight $(\mathrm{P}<0.05)$ were significantly correlated with the occurrence of dyslipidemia. When age, menopausal status, PR status and weight were included into the multivariate analysis, it was observed that age was remained as an independent predictor of dyslipidemia with odds ratio (OR) of $1.796(95 \% \mathrm{CI}: 1.402-2.302, \mathrm{P}<0.05)$ and 2.976 (95\% CI:1.889-4.688, $\mathrm{P}<0.05$ ), along with menopausal status (OR: 2.143, 95\% CI:1.636-2.808, $\mathrm{P}<0.05$ ) and weight (OR:1.407, 95\% CI:1.140-1.737, $\quad \mathrm{P}<0.05)$. However, multivariate analysis showed that PR status $(\mathrm{P}>0.05)$ had no predictive value for dyslipidemia.

The alterations in the levels of serum lipids and apolipoproteins of 1740 patients during chemotherapy are displayed in Figure 1. The levels of TG for the patients receiving chemotherapy gradually increased $(\mathrm{P}<0.05)$ and HDL-C gradually decreased $(\mathrm{P}<0.05)$ during the treatment $(\mathrm{P}<0.05)$. Compared with those before chemotherapy, the levels of TC and LDL-C reduced after the first cycle, but which significantly increased before the last cycle and showed higher $(\mathrm{P}<0.05)$. No significant difference was observed in Lpa before and after the first cycle of chemotherapy $(\mathrm{P}>0.05)$, but it did increase before the last cycle $(\mathrm{P}<0.05)$.

\section{Comparison of the Levels of Serum Lipids in the Same Regimens}

Three hundred and eighty-five breast cancer patients accepted the dose-dense chemotherapy regimens (a) with EC-P every 2 weeks and 502 patients received the standard-interval chemotherapy regimens (b) including EC-D every 3 weeks (Figure 2). The TG levels increased $(\mathrm{P}<0.05)$ while the HDL-C levels decreased $(\mathrm{P}<0.05)$ during the treatment of these two regimens. In the previous regimen, TC, LDL-C and Lpa reduced after the first cycle but increased before the last cycle of chemotherapy $(\mathrm{P}<0.05)$; however, no difference was observed between the levels of before chemotherapy and before the last cycle of chemotherapy in LDL-C and Lpa $(\mathrm{P}>0.05)$. In the latter regimen, TC, LDL-C and Lpa increased before the last cycle in contrast to those before and after the first cycle $(\mathrm{P}<0.05)$. 
Table I Baseline Characteristics of the Study Population

\begin{tabular}{|c|c|c|}
\hline Characteristics & $\mathbf{N}$ & $\%$ \\
\hline \multicolumn{3}{|l|}{ Age } \\
\hline$\leq 45$ & 707 & 40.63 \\
\hline $45-60$ & 843 & 48.45 \\
\hline$>60$ & 190 & 10.92 \\
\hline \multicolumn{3}{|l|}{ Menopausal status } \\
\hline Premenopausal period & 1016 & 58.39 \\
\hline Perimenopausal period & 93 & 5.35 \\
\hline Postmenopausal period & 627 & 36.03 \\
\hline Missing & 4 & 0.23 \\
\hline \multicolumn{3}{|l|}{ Tumor size } \\
\hline TI & 750 & 43.11 \\
\hline $\mathrm{T} 2$ & 798 & 45.86 \\
\hline $\mathrm{T} 3$ & 47 & 2.70 \\
\hline Missing & 145 & 8.33 \\
\hline \multicolumn{3}{|l|}{ Nodal stage } \\
\hline No & 949 & 54.54 \\
\hline $\mathrm{NI}$ & 429 & 24.66 \\
\hline N2 & 177 & 10.17 \\
\hline N3 & 109 & 6.26 \\
\hline Missing & 76 & 4.37 \\
\hline \multicolumn{3}{|l|}{ Histological grade } \\
\hline 1 & 20 & 1.15 \\
\hline II & 649 & 37.30 \\
\hline III & 868 & 49.88 \\
\hline Missing & 203 & 11.67 \\
\hline \multicolumn{3}{|l|}{ ER } \\
\hline Positive & 1169 & 67.18 \\
\hline Negative & 480 & 27.59 \\
\hline Missing & 91 & 5.23 \\
\hline \multicolumn{3}{|l|}{ PR } \\
\hline Positive & 990 & 56.90 \\
\hline Negative & 659 & 37.87 \\
\hline Missing & 91 & 5.23 \\
\hline \multicolumn{3}{|l|}{ HER-2 } \\
\hline Positive & 462 & 26.55 \\
\hline Negative & 1153 & 66.27 \\
\hline Missing & 125 & 7.18 \\
\hline \multicolumn{3}{|l|}{ Ki67 } \\
\hline$\leq 14 \%$ & 284 & 16.32 \\
\hline$>14 \%$ & 1344 & 77.24 \\
\hline Missing & 112 & 6.44 \\
\hline \multicolumn{3}{|l|}{ Molecular subtype } \\
\hline Luminal A & 160 & 9.19 \\
\hline Luminal B & 1006 & 57.82 \\
\hline HER-2 & $|8|$ & 10.40 \\
\hline Triple negative & 266 & 15.29 \\
\hline
\end{tabular}

(Continued)
Table I (Continued).

\begin{tabular}{|c|l|l|}
\hline Characteristics & N & $\%$ \\
\hline Missing & 127 & 7.30 \\
\hline Weight $(\mathrm{kg})$ & & \\
$\leq 60$ & 1015 & 58.33 \\
$>60$ & 709 & 40.75 \\
Missing & 16 & 0.92 \\
\hline
\end{tabular}

Then, the anthracycline-based chemotherapy regimens (A) containing anthracycline were selected, which involved 683 breast cancer patients who received EC and the first four times of the cycles of EC-D. One hundred and thirty-nine patients received the taxane-based chemotherapy regimens (B) containing taxane, which consisted of TC every 3 weeks for four or six cycles. Seven hundred and eighty-one patients obtained the anthracycline-plus-taxane-based chemotherapy regimens (C) containing anthracycline and taxane, which included EC-D without Trastuzumab or Capecitabine, EC-P without Trastuzumab and TEC (Figure 3). It was found that TG gradually increased and HDL-C decreased during the treatment $(\mathrm{P}<0.05)$ of these three regimens. Compared with the values before the first cycle of chemotherapy in A, TC, LDL-C and Lpa levels significantly increased before the last cycle $(\mathrm{P}<0.05)$. In $\mathrm{B}, \mathrm{TC}, \mathrm{LDL}-\mathrm{C}$ and $\mathrm{Lpa}$ increased after the first cycle $(\mathrm{P}<0.05)$ but no difference was demonstrated between their respective levels after the first cycle and before the last cycle of chemotherapy $(\mathrm{P}>0.05)$. In $\mathrm{C}, \mathrm{TC}$, LDL-C and Lpa decreased after the first cycle but increased before the last cycle of chemotherapy $(\mathrm{P}<0.05)$; however, no statistical difference was revealed between the levels of Lpa before chemotherapy and before the last cycle of chemotherapy $(\mathrm{P}>0.05)$.

\section{Comparison of the Levels of Serum Lipids in Different Regimens}

The levels of serum lipids and apolipoproteins of breast cancer patients treated with dose-dense chemotherapy regimens and standard-interval ones were compared (Figure 4). All data showed that there were no statistical differences between the two chemotherapy regimens before chemotherapy. The level of TG with the standardinterval chemotherapy regimens showed higher than the level with the dose-dense ones after the first cycle of chemotherapy $(\mathrm{P}<0.05)$, but the status was reversed before 
Table 2 Predictive Factors for Dyslipidemia in Univariate Analyses

\begin{tabular}{|c|c|c|c|c|}
\hline Variables & $\begin{array}{l}\text { Total } \\
\text { (N) }\end{array}$ & $\begin{array}{l}\text { Normal } \\
\text { Group (N) }\end{array}$ & $\begin{array}{l}\text { Dyslipidemia } \\
\text { Group (N) }\end{array}$ & $\mathbf{p}^{\mathbf{a}}$ \\
\hline Age & & & & $<0.05$ \\
\hline$\leqq 45$ & 707 & 425 & 282 & \\
\hline $45-60$ & 843 & 309 & 534 & \\
\hline$>60$ & 190 & 43 & 147 & \\
\hline Menopausal status & & & & $<0.05$ \\
\hline $\begin{array}{l}\text { Premenopausal } \\
\text { period }\end{array}$ & 1016 & 563 & 453 & \\
\hline $\begin{array}{l}\text { Perimenopausal } \\
\text { period }\end{array}$ & 93 & 38 & 55 & \\
\hline $\begin{array}{l}\text { Postmenopausal } \\
\text { period }\end{array}$ & 627 & 175 & 452 & \\
\hline Missing & 4 & 1 & 3 & \\
\hline Tumor size & & & & 0.056 \\
\hline TI & 751 & 340 & 411 & \\
\hline T2 & 798 & 332 & 466 & \\
\hline $\mathrm{T} 3$ & 47 & 27 & 20 & \\
\hline Missing & 144 & 78 & 66 & \\
\hline Nodal stage & & & & 0.081 \\
\hline No & 949 & 430 & 519 & \\
\hline $\mathrm{NI}$ & 429 & 169 & 260 & \\
\hline N2 & 177 & 86 & 91 & \\
\hline N3 & 109 & 53 & 56 & \\
\hline Missing & 76 & 39 & 37 & \\
\hline Histological grade & & & & 0.519 \\
\hline 1 & 20 & II & 9 & \\
\hline II & 650 & 295 & 355 & \\
\hline III & 867 & 379 & 488 & \\
\hline Missing & 203 & 92 & 111 & \\
\hline ER & & & & 0.077 \\
\hline Positive & 1169 & 538 & 631 & \\
\hline Negative & 480 & 198 & 282 & \\
\hline Missing & 91 & 41 & 50 & \\
\hline PR & & & & $<0.05$ \\
\hline Positive & 988 & 472 & 516 & \\
\hline Negative & 661 & 264 & 397 & \\
\hline Missing & 91 & 41 & 50 & \\
\hline HER-2 & & & & 0.319 \\
\hline Positive & 463 & 215 & 248 & \\
\hline Negative & 1153 & 504 & 649 & \\
\hline Missing & 124 & 58 & 66 & \\
\hline Ki67 & & & & 0.482 \\
\hline$\leqq 14 \%$ & 284 & 132 & 152 & \\
\hline$>14 \%$ & 1344 & 594 & 750 & \\
\hline Missing & 112 & 51 & 61 & \\
\hline Molecular subtype & & & & 0.199 \\
\hline Luminal A & 160 & 77 & 83 & \\
\hline Luminal B & 1006 & 459 & 547 & \\
\hline
\end{tabular}

(Continued)
Table 2 (Continued).

\begin{tabular}{|l|l|l|l|l|}
\hline Variables & $\begin{array}{l}\text { Total } \\
\mathbf{( N )}\end{array}$ & $\begin{array}{l}\text { Normal } \\
\text { Group (N) }\end{array}$ & $\begin{array}{l}\text { Dyslipidemia } \\
\text { Group (N) }\end{array}$ & $\mathbf{p}^{\mathbf{a}}$ \\
\hline HER-2 & 181 & 74 & 107 & \\
$\begin{array}{l}\text { Triple negative } \\
\text { Missing }\end{array}$ & 266 & 106 & 160 & \\
\hline $\begin{array}{l}\text { Weight (kg) } \\
\leqq 60\end{array}$ & 127 & 61 & 66 & \\
$>60$ & 1015 & 496 & 519 & $<0.05$ \\
Missing & 709 & 272 & 437 & \\
\hline
\end{tabular}

Note: a Calculated by chi-square test as univariate analyses.

Table 3 Predictive Factors for Dyslipidemia in Multivariate Analyses

\begin{tabular}{|c|c|c|}
\hline Variables & Multivariate OR $(95 \% \mathrm{Cl})^{\mathrm{a}}$ & $\mathbf{p}^{\mathbf{a}}$ \\
\hline $\begin{array}{l}\text { Age } \\
\qquad \leqq 45\end{array}$ & & $<0.05$ \\
\hline $45-60$ & $1.796(1.402-2.302)$ & $<0.05$ \\
\hline$>60$ & $2.976(1.889-4.688)$ & $<0.05$ \\
\hline $\begin{array}{l}\text { Menopausal status } \\
\text { Premenopausal period }\end{array}$ & & $<0.05$ \\
\hline Perimenopausal period & & 0.229 \\
\hline $\begin{array}{l}\text { Postmenopausal period } \\
\text { Missing }\end{array}$ & $2.143(1.636-2.808)$ & $<0.05$ \\
\hline $\begin{array}{l}\text { PR } \\
\text { Positive } \\
\text { Negative } \\
\text { Missing }\end{array}$ & & 0.192 \\
\hline $\begin{array}{l}\text { Weight (kg) } \\
\leqq 60 \\
>60 \\
\text { Missing }\end{array}$ & $1.407(1.140-1.737)$ & $<0.05$ \\
\hline
\end{tabular}

Note: ${ }^{\mathrm{C} C a l c u l a t e d ~ b y ~ m u l t i v a r i a t e ~ b i n a r y ~ l o g i s t i c ~ r e g r e s s i o n ~ a n a l y s i s . ~}$

Abbreviations: OR, odds ratio; $\mathrm{Cl}$, confidence interval.

the last cycle $(\mathrm{P}<0.05)$. TC, HDL-C and LDL-C with the standard-interval chemotherapy regimens were higher than those with the dose-dense ones after the first and before the last cycles of chemotherapy $(\mathrm{P}<0.05)$. No statistical difference in Lpa existed between the two chemotherapy groups $(\mathrm{P}>0.05)$.

The levels of serum lipids and apolipoproteins with anthracycline-based regimens (A), taxane-based regimens (B) and anthracycline-plus-taxane-based regimens (C) were compared, whose results are shown in Figure 5. Comparisons of the levels of serum lipids among the three chemotherapy regimens were made, whose adjusted 


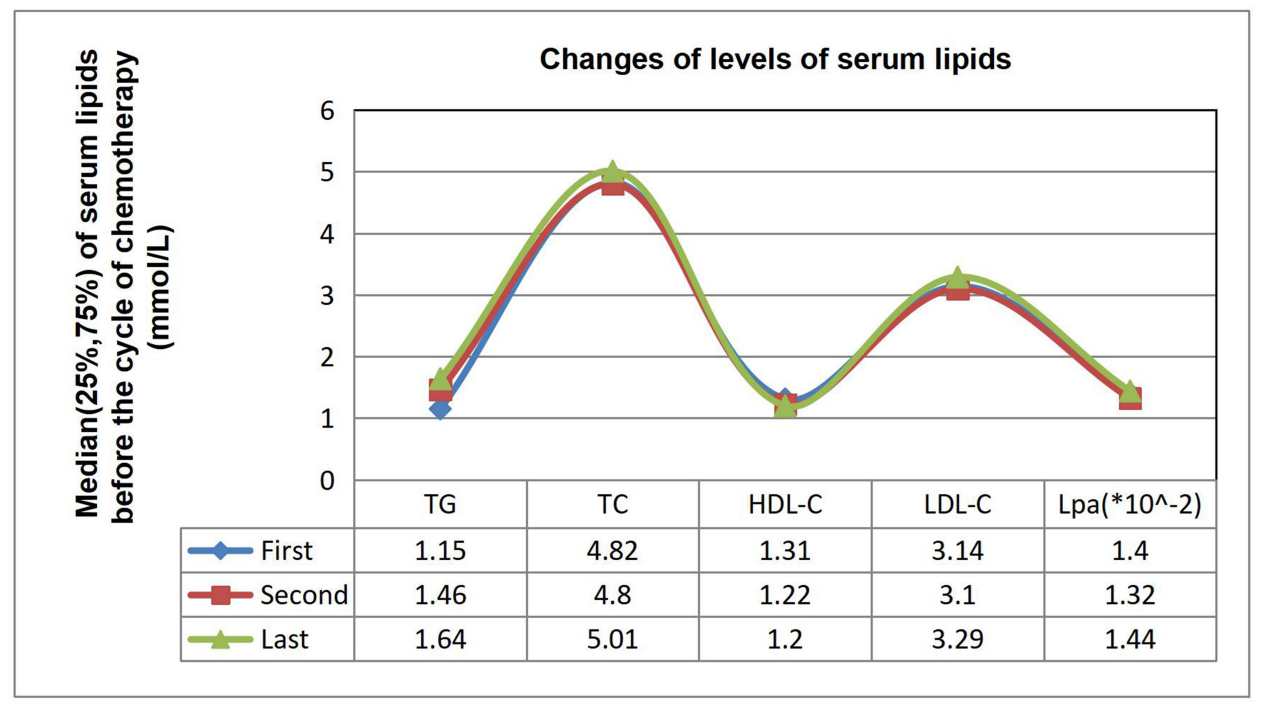

Figure I Changes of levels of serum lipids in 1740 patients during chemotherapy. $\mathrm{P}<0.05$ was considered to be statistically significant. All changes were statistically significant except Lpa prior to first and second, second and last cycles of chemotherapy.

p-value for significance was 0.008333 . No statistical difference was shown in serum lipids and apolipoproteins among the three chemotherapy regimens before chemotherapy ( $\mathrm{P}>0.05)$. Comparing the serum lipids of $\mathrm{A}$ to $\mathrm{B}$, TG showed higher $(\mathrm{P}<0.008333)$, but TC and LDL-C were lower after the first cycle $(\mathrm{P}<0.008333)$, and HDL-C was also lower after the first and before the last cycles of chemotherapy $(\mathrm{P}<0.008333)$. Comparing the serum lipids of A to $\mathrm{C}$, TG demonstrated lower before the last cycle, but TC and LDL-C were higher after the first cycle of chemotherapy $(\mathrm{P}<0.008333)$. Comparing the serum lipids of $\mathrm{B}$ to $\mathrm{C}$, TG displayed lower and HDL-C was higher after the first and before the last cycles $(\mathrm{P}<0.008333)$, TC and LDL-C were higher after the first cycle of chemotherapy $(\mathrm{P}<0.008333)$.

\section{Discussion}

The predictive factors of dyslipidemia in breast cancer patients before chemotherapy were founded through univariate and multivariate analysis in the retrospective cohort study. In accordance with previous studies, the age, menopausal status and weight of the patients were closely related to dyslipidemias, ${ }^{18,19}$ which suggested that breast cancer patients were more prone to have dyslipidemias with the increases of age and weight. ${ }^{20}$ Furthermore, postmenopausal patients had a higher risk of dyslipidemia than premenopausal and perimenopausal patients. ${ }^{21}$

Recently, adjuvant chemotherapy has improved the disease-free survival and overall survival of breast cancer patients; however, the detrimental effects caused by chemotherapy remain unclear. ${ }^{22-25}$ We specifically assessed the changes of serum lipids and apolipoproteins following the administration of chemotherapy in breast cancer patients. When the postoperative patients received chemotherapy, their levels of TC and LDL-C reduced after the first cycle because cancer drugs needed cholesterol depletion to cross the cell membranes. ${ }^{26}$ However, the TG, TC, LDL-C and Lpa were significantly increased and HDL-C was decreased before the last cycle, which was consistent with previous research results, ${ }^{27,28}$ and further confirmed that chemotherapy had adverse effects on postoperative serum lipids of breast cancer patients. The mechanism could be as follows: chemotherapy directly led to endothelial dysfunction and changes in cytokines; chemotherapy caused lipid peroxidation by enhancing systemic oxidative stress to affect the function of liver cells; Meanwhile, chemotherapy affected lipid metabolism by changing the plasma adiponectin level resulting in changes in serum lipid levels. ${ }^{29-31}$ Previous studies had revealed that dyslipidemias could also be triggered by endocrine therapy and lipid-lowering therapy was a very successful strategy to prevent cardiovascular events. ${ }^{32,33}$ Additionally, dyslipidemias in lung cancer had been proved to increase the activity of tumor cells and reduce their sensitivity to chemotherapy, while its effects on chemotherapy in breast cancer could not be ruled out yet. ${ }^{34}$ Thus, it is essential to take certain interventional measures against dyslipidemias in the process of breast cancer treatment. 

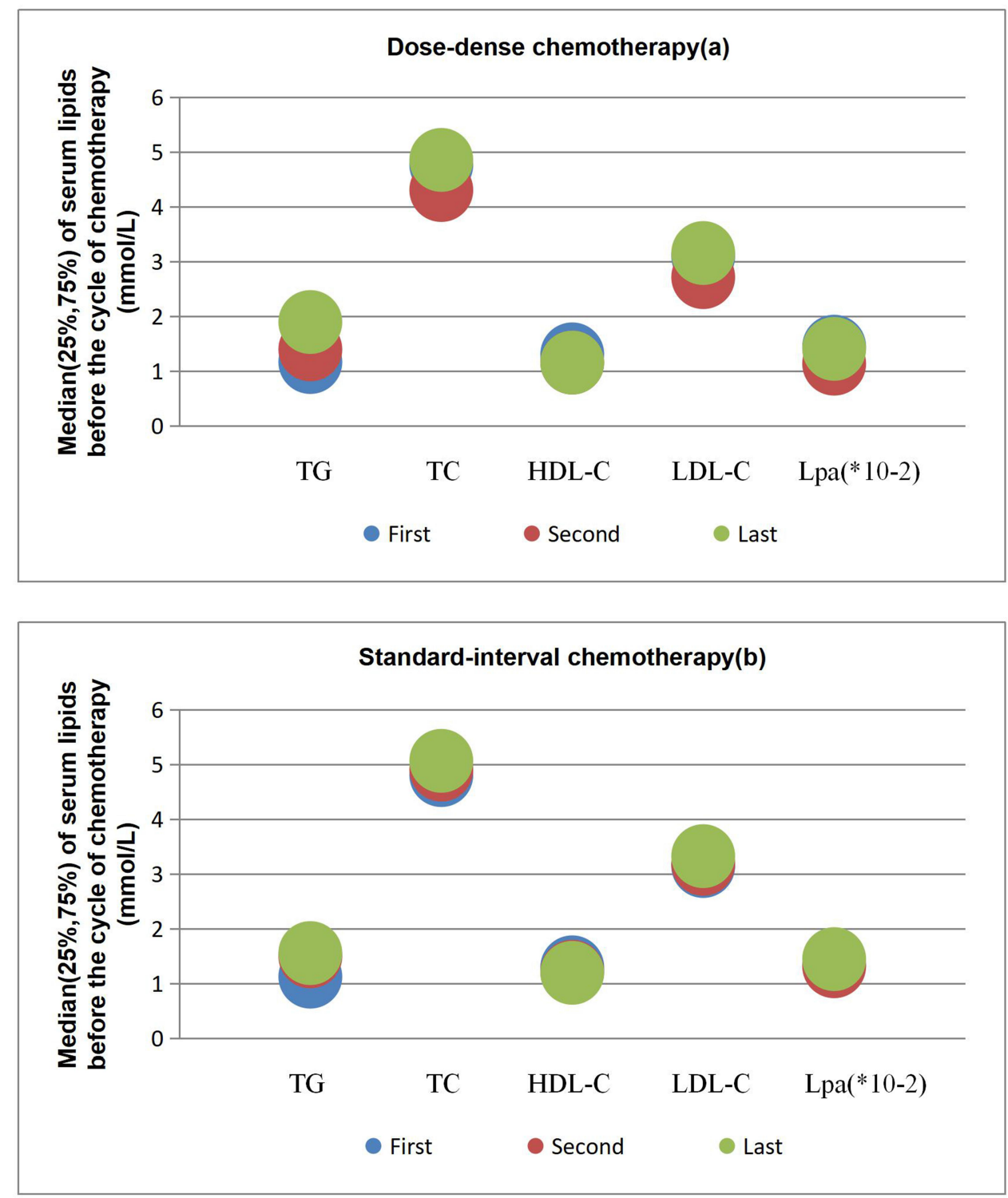

Figure 2 Changes of levels of serum lipids during dose-dense (a) and standard-interval (b) chemotherapy. P $<0.05$ was considered to be statistically significant. All changes were statistically significant except HDL-C prior to second and last, LDL-C and Lpa prior to first and last cycles in dose-dense chemotherapy and TC, LDL-C and Lpa prior to first and second cycles in standard-interval chemotherapy.

The interval between chemotherapy cycles was regarded as one of the key factors affecting the efficacy of chemotherapy in breast cancer. ${ }^{35}$ Many studies reported that the efficacy of dose-dense chemotherapy showed better than that of standard-interval chemotherapy, but few studies compared the differences in their effects on serum lipid levels. ${ }^{36,37}$ Previous studies suggested that dose-dense and standardinterval regimens had a similar incidence of myelosuppression, ${ }^{38}$ while the results for dyslipidemias were different. After dose-dense chemotherapy, increases in TG and TC, decreases in HDL-C and no significant change in LDL-C and Lpa were observed. TG, TC, LDL-C and Lpa increased but HDL-C reduced after standard-interval chemotherapy. Due to the same number of chemotherapy cycles, the interval between cycles and the total time of standard-interval regimens were longer than that of dosedense regimens, and the standard-interval regimens included docetaxel and the dose-dense regimens included paclitaxel. Therefore, the use of docetaxel and the extension of chemotherapy time may cause changes in LDL-C and Lpa. Comparing the two regimens, it was found that TC, HDL-C and LDL-C with standard-interval regimens were higher than those with dose-dense ones. TG with standard-interval regimens was higher than that with dose-dense ones after the first cycle of chemotherapy, but lower before the last cycle of chemotherapy. Obviously, the changes of TC and LDL-C 

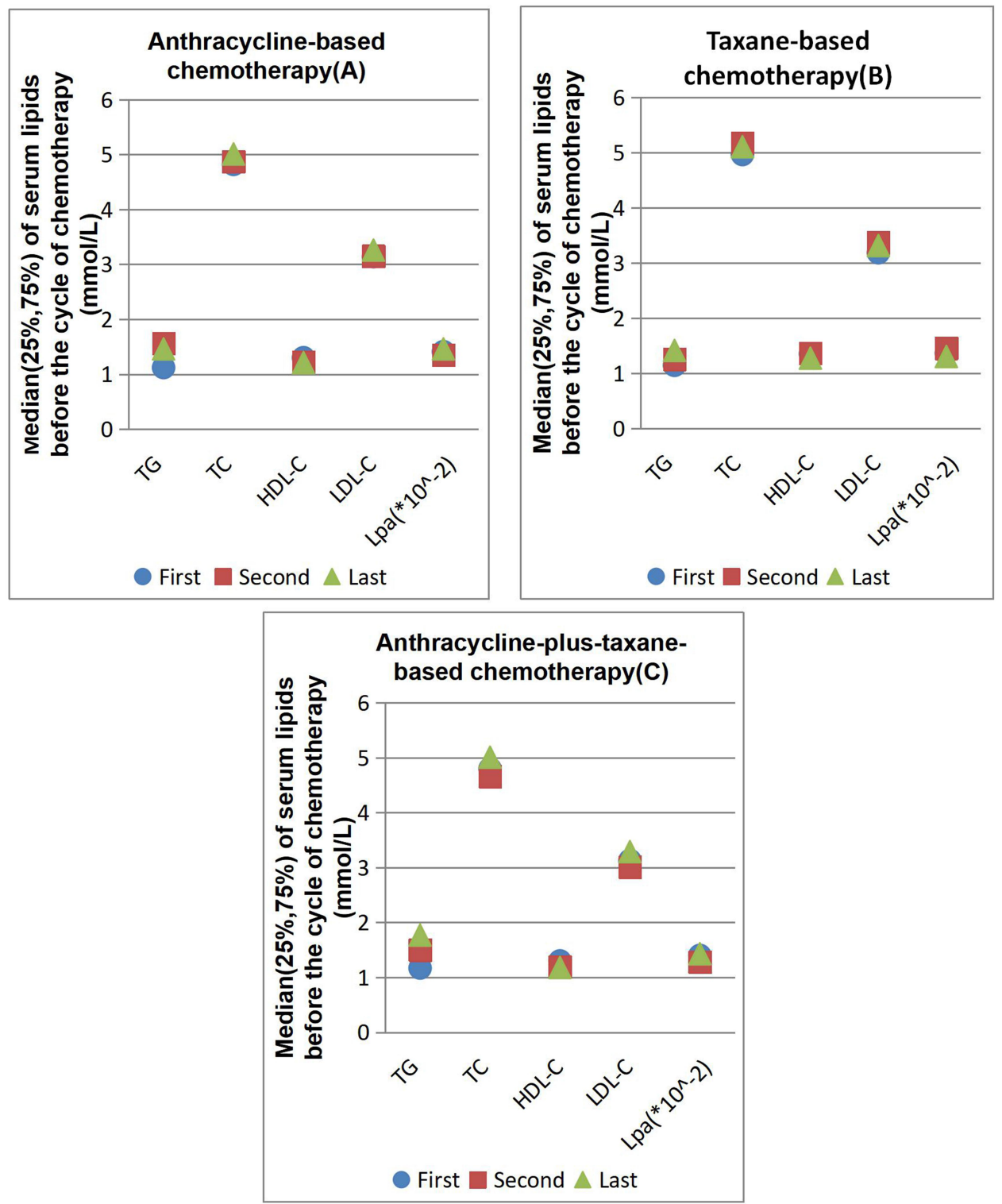

Figure 3 Changes of levels of serum lipids during anthracycline-based (A), taxane-based (B) and anthracycline-plus-taxane-based (C) chemotherapy. All changes were statistically significant except TC, LDL-C and Lpa prior to first and second, Lpa prior to second and last cycles in A, HDL-C prior to first and second, TC, LDL-C and Lpa prior to second and last cycles in B, and Lpa prior to first and last cycles in C.

increased with the extension of the total time of chemotherapy and the use of docetaxel, and the changes of TG and HDL-C increased with the increase of the frequency of chemotherapy and the use of paclitaxel, which was related to the inactivation of cholesterol biosynthesis pathway following paclitaxel treatment. ${ }^{39}$ Since there was no difference in drugs, dose and frequency between the two chemotherapy regimens for the first cycle, the difference in serum lipid levels after the first cycle of chemotherapy might be attributed to the deviations from the clinician's chemotherapy regimen based on the clinicopathological information of the patients. Whether there is an increase of TG, TC and LDL-C or a decrease of HDL-C in elderly, postmenopausal and less tumor-bearing patients after chemotherapy, we need more prospective studies to prove it.

It is well known that anthracycline is the cornerstone of breast cancer chemotherapy; Meanwhile, taxane has been widely adopted in the treatment of breast cancer patients. ${ }^{40-42}$ Many clinical trials had found that the taxane incorporated into anthracycline-based chemotherapy regimens could prolonge the disease-free survival and overall survival of breast cancer patients. ${ }^{42-44}$ This study observed that the levels of TG, TC, LDL-C and Lpa in breast cancer patients increased significantly, while the levels of HDL-C obviously decreased after 


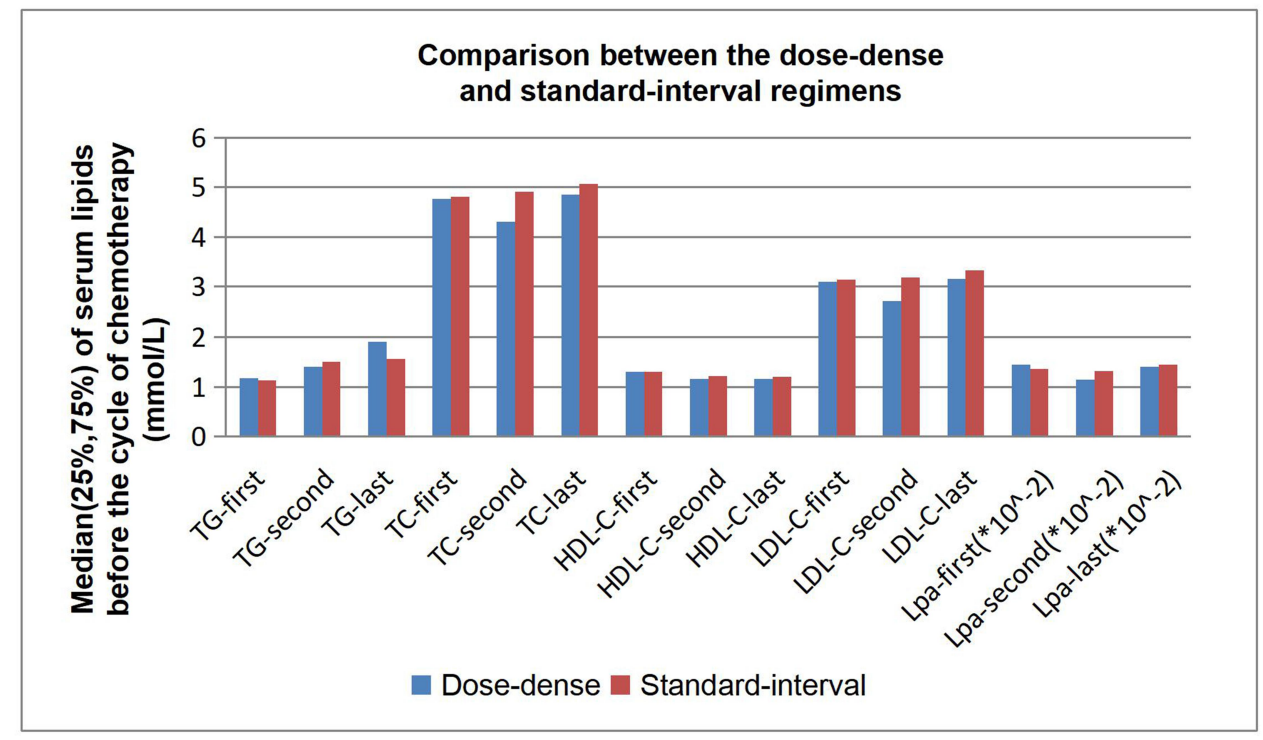

Figure 4 Comparison between the dose-dense and standard-interval regimens. $\mathrm{P}<0.05$ was considered to be statistically significant. There was statistical difference in TGsecond, TG-last, TC-second, TC-last, HDL-C-second, HDL-C-last, LDL-C-second and LDL-C-last between dose-dense and standard-interval regimens.

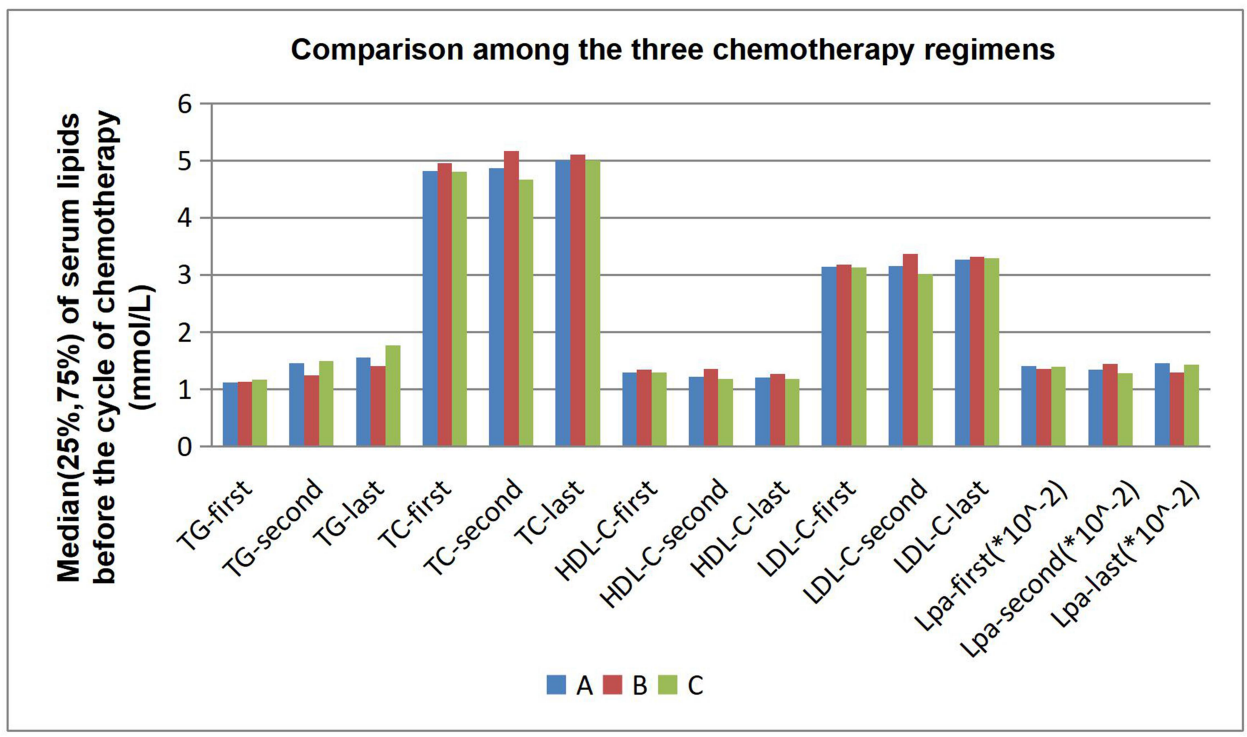

Figure 5 Comparison among anthracycline-based regimens (A), taxane-based regimens (B) and anthracycline-plus-taxane-based regimens (C). The adjusted p-value for significance was 0.008333 . There was statistical difference in TG-second, TC-second, HDL-C-second, HDL-C-last and LDL-C-second between A and B, TG-last, TC-second and LDL-C-second between A and C, TG-second, TG-last, TC-second, HDL-C-second, HDL-C-last and LDL-C-second between B and C.

anthracycline-based chemotherapy, which was consistent with previous findings. ${ }^{45}$ Some studies proposed that anthracyclines affected hepatocytes metabolism of serum lipids and lipoproteins by reducing the efficiency of mitochondrial respiration and the content of cytoplasmic adenosine triphosphate. ${ }^{46}$ Previous studies confirmed taxanes increased the risk of dyslipidemias by inhibiting TC from entering cells, reducing the level of LDL-C receptor protein and promoting the degradation of HDL-C. ${ }^{47}$ This study found that TG, TC, LDL-C and
Lpa increased rapidly after patients received the first cycle of taxane-based chemotherapy, while HDL-C as a protective factor for cardiovascular disease did not decrease until the last cycle of chemotherapy. However, studies by Panis et al indicated that the levels of HDL-C, LDL-C and lipoprotein in breast cancer patients injected with short-term single-dose paclitaxel in the first cycle of chemotherapy were significantly lower than those without chemotherapy. ${ }^{31}$ It was believed that this variation could be related to the difference in the time of 
obtaining blood samples after the first chemotherapy, which was 3 weeks after chemotherapy in this study, whereas it was 3 $\mathrm{h}$ after chemotherapy in C. Panis' study. In addition, this study disclosed that the levels of TG, TC and LDL-C increased significantly and HDL-C obviously decreased in breast cancer patients after anthracycline-plus-taxane-based chemotherapy regimens. This result was basically consistent with the results of Bicakli et al, but they found that although the LDL-C of the patients increased, it did not reach the statistical significance. ${ }^{9}$ It can be seen that regardless of whether the chemotherapy regimen of breast cancer patients use anthracyclines, taxanes or anthracyclines plus taxanes, abnormalities in serum lipids are almost inevitable. In view of the widespread use of anthracyclines and taxanes in breast cancer chemotherapy, it is conceivable that chemotherapy can lead to dyslipidemias.

In this study, the different effects of anthracycline-based, taxane-based and anthracycline-plus-taxane-based chemotherapy regimens on serum lipids and lipoprotein levels of postoperative breast cancer patients were compared for the first time. In contrast to taxanes, anthracyclines had a greater effect on TG and HDL-C but had a less impact on TC and LDL-C after the first cycle of chemotherapy. Previous studies pointed out that anthracyclines altered TG levels by promoting apoptosis of vascular endothelial cells. ${ }^{48}$ Except for HDL-C, the other parameters of the two groups were not statistically significant before the last chemotherapy cycle. Anthracyclines were more likely to cause dyslipidemias than taxanes because of their effect on HDL-C. ${ }^{47}$ Compared with anthracycline-plus-taxane-based regimens, TG with anthracycline-based regimens showed lower before the last cycle of chemotherapy, while TC and LDL-C were higher after the first cycle of chemotherapy. Although the short-term effect of anthracyclines plus taxanes on serum lipids was less than that of anthracyclines, the long-term effect was greater than that of anthracyclines, which could be associated with the greater number of chemotherapy cycles. Considering that there was no difference in drugs, dose and frequency between the two first cycles of chemotherapy, it seemed that TC and LDL-C increased more in elderly patients, postmenopausal patients and patients with low tumor load after chemotherapy, which was consistent with our previous speculation. Compared with the anthracycline-plus-taxane-based regimens, patients with taxane-based regimens indicated lower TG levels and higher HDL-C levels after the first cycle and before the last cycle of chemotherapy, but higher TC and LDL-C levels after the first cycle of chemotherapy. Anthracycline plus taxanes had a greater impact on serum lipids than taxanes. ${ }^{49}$ It was obvious that anthracyclines plus taxanes were more likely to cause dyslipidemias than anthracyclines, which was more likely to cause dyslipidemias than taxanes. Anthracyclines had a greater effect on TG and HDL-C, while taxanes had a greater effect on TC and LDL-C. Therefore, this result could provide evidence for the selection of lipid-lowering drugs during chemotherapy, and proved that taxanes could be used as the chemotherapy options for patients with high-risk cardiovascular events like hyperlipidemia.

Despite the positive results, the study had some limitations. First of all, as a retrospective study, some relevant influencing factors could not be completely excluded. Secondly, even though the timepoint "after the last chemotherapy" better indicated the effect of chemotherapy on serum lipids, we still selected the timepoint "before the last cycle of chemotherapy" to avoid interference with radiotherapy or endocrine therapy. So our results were still required to be supplemented through rigorous prospective studies. Lastly, our study only evaluated the changes in serum lipids before and during chemotherapy, but lacked the prognostic value of later follow-up. Obviously, the improvement of this part has been carried out.

\section{Conclusion}

In conclusion, it was found that chemotherapy resulted in high levels of TG, TC, LDL-C and Lpa and low levels of HDL-C, which could lead to a higher risk of dyslipidemias. Moreover, a significant difference in the changes in levels of serum lipids existed in patients with different chemotherapy regimens. Patients with high TC and LDL$\mathrm{C}$ were more suitable for dose-dense chemotherapy, while patients with high TG and low HDL-C were more suitable for standard-interval one. Furthermore, compared with anthracycline and anthracycline plus taxane regimens, taxane was more suitable for patients with dyslipidemias. As chemotherapy-related side effects are gradually attracting more and more attention, the results can provide guidance for the chemotherapy regimens, as well as the intervention measures and appropriate timing to control the dyslipidemias before and during chemotherapy.

\section{Funding}

This work was supported by the National Natural Science Foundation of China (Grant No. 81572602).

\section{Disclosure}

The authors declare no conflict of interests for this work. 


\section{References}

1. DeSantis CE, Ma J, Gaudet MM, et al. Breast cancer statistics, 2019. CA Cancer J Clin. 2019;69:438-451. doi:10.3322/caac.21583

2. Torre LA, Bray F, Siegel RL, Ferlay J, Lortet-Tieulent J, Jemal A. Global cancer statistics, 2012. CA Cancer J Clin. 2015;65:87-108. doi: $10.3322 /$ caac. 21262

3. Hong W, Dong E. The past, present and future of breast cancer research in China. Cancer Lett. 2014;351:1-5. doi:10.1016/j. canlet.2014.04.007

4. Sankatsing VDV, van Ravesteyn NT, Heijnsdijk EAM, et al. The effect of population-based mammography screening in Dutch municipalities on breast cancer mortality: 20 years of follow-up. Int J Cancer. 2017;141:671-677. doi:10.1002/ijc.30754

5. Donald A, Berry PD, Kathleen AC, et al., for the Cancer Intervention and Surveillance Modeling Network (CISNET) Collaborators*. Effect of screening and adjuvant therapy on mortality from breast cancer.pdf. The New England. J Med. 2005;353:1784-1792.

6. Anampa J, Makower D, Sparano JA. Progress in adjuvant chemotherapy for breast cancer: an overview. BMC Med. 2015;13:195 doi:10.1186/s12916-015-0439-8

7. Shachar SS, Deal AM, Weinberg M, et al. Body composition as a predictor of toxicity in patients receiving anthracycline and taxane-based chemotherapy for early-stage breast cancer. Clin Cancer Res. 2017;23:3537-3543. doi:10.1158/1078-0432.CCR-16-2266

8. Beusterien K, Grinspan J, Kuchuk I, et al. Use of conjoint analysis to assess breast cancer patient preferences for chemotherapy side effects. Oncologist. 2014;19:127-134. doi:10.1634/theoncologist.2013-0359

9. Bicakli DH, Varol U, Degirmenci M, et al. Adjuvant chemotherapy may contribute to an increased risk for metabolic syndrome in patients with breast cancer. J Oncol Pharm Pract. 2016;22:46-53. doi:10.1177/1078155214551315

10. Rzymowska J. Effect of cytotoxic chemotherapy on serum lipid levels in breast cancer patients.pdf. Pathobiology. 1999;67:129-132. doi: $10.1159 / 000028062$

11. Rachel Huxley DP, Sarah Lewington D, Robert C. Cholesterol, coronary heart disease and stroke- a review of published evidence from observational studies and randomized controlled trials.pdf. Semin Vasc Med. 2002;2:315-323. doi:10.1055/s-2002-35402

12. Averina M, Nilssen O, Brenn T, Brox J, Arkhipovsky VL, Kalinin AG. Factors behind the increase in cardiovascular mortality in Russia: apolipoprotein AI and B distribution in the Arkhangelsk study 2000. Clin Chem. 2004;50:346-354. doi:10.1373/ clinchem.2003.023853

13. Li X, Liu ZL, Wu YT, et al. Status of lipid and lipoprotein in female breast cancer patients at initial diagnosis and during chemotherapy. Lipids Health Dis. 2018;17:91. doi:10.1186/s12944-018-0745-1

14. Arpino G, De Angelis C, Buono G, et al. Metabolic and anthropometric changes in early breast cancer patients receiving adjuvant therapy. Breast Cancer Res Treat. 2015;154:127-132. doi:10.1007/ s10549-015-3586-x

15. Feola A, Ricci S, Kouidhi S, et al. Multifaceted breast cancer: the molecular connection with obesity. J Cell Physiol. 2017;232:69-77. doi: $10.1002 /$ jcp. 25475

16. Martin LJ, Melnichouk O, Huszti E, et al. Serum lipids, lipoproteins, and risk of breast cancer: a nested case-control study using multiple time points. $J$ Natl Cancer Inst. 2015;107.

17. Yeo W, Mo FKF, Pang E, et al. Profiles of lipids, blood pressure and weight changes among premenopausal Chinese breast cancer patients after adjuvant chemotherapy. BMC Womens Health. 2017;17:55. doi:10.1186/s12905-017-0409-8

18. Bulut T, Demirel F, Metin A. The prevalence of dyslipidemia and associated factors in children and adolescents with type 1 diabetes. J Pediatr Endocrinol Metab. 2017;30:181-187. doi:10.1515/jpem2016-0111
19. Choi Y, Chang Y, Kim BK, et al. Menopausal stages and serum lipid and lipoprotein abnormalities in middle-aged women. Maturitas. 2015;80:399-405. doi:10.1016/j.maturitas.2014.12.016

20. Pan L, Yang Z, Wu Y, et al.; China National Survey of Chronic Kidney Disease Working G. The prevalence, awareness, treatment and control of dyslipidemia among adults in China. Atherosclerosis. 2016;248:2-9. doi:10.1016/j.atherosclerosis.2016.02.006

21. Shilpa S, Shende MVB, apte IC, ViShaKha VM, harShal PN. Study of lipid profile and c reactive protein in pre-and post-menopausal women.pdf. J Clin Diagnostic Res. 2011;5:1544-1547.

22. Harbeck N. Advances in targeting HER2-positive breast cancer. Curr Opin Obstet Gynecol. 2018;30:55-59. doi:10.1097/GCO.0000000 000000431

23. Robert Havard NLH. Integrating clinicopathologic and genomic tools in chemotherapy decision-making for early stage breast cancer. Pdf Future Oncol. 2017;13:2507-2510. doi:10.2217/fon2017-0452

24. Ladwa R, Sanmugarajah J. The feasibility and tolerability of newer chemotherapy regimens in the adjuvant setting in older patients with breast cancer. Breast J. 2016;22:244-246. doi:10.1111/ tbj. 12559

25. Koga C, Akiyoshi S, Ishida M, Nakamura Y, Ohno S, Tokunaga E. Chemotherapy-induced amenorrhea and the resumption of menstruation in premenopausal women with hormone receptor-positive early breast cancer. Breast Cancer. 2017;24:714-719. doi:10.1007/s12282-0170764-1

26. Zhang L, Bennett WF, Zheng T, et al. Effect of cholesterol on cellular uptake of cancer drugs pirarubicin and ellipticine. J Phys Chem B. 2016;120:3148-3156. doi:10.1021/acs.jpcb.5b12337

27. Alexopoulos SP CG, Vaslamatzis M, Avgerinos A, Raptis S. Changes in serum lipids and lipoproteins in cancer patients during chemotherapy.pdf. Cancer Chemother Pharmaco. 1992;30:412-416. doi:10.1007/BF00689971

28. Dieli-Conwright CM, Wong L, Waliany S, Bernstein L, Salehian B, Mortimer JE. An observational study to examine changes in metabolic syndrome components in patients with breast cancer receiving neoadjuvant or adjuvant chemotherapy. Cancer. 2016;122:2646-2653. doi:10.1002/cncr.30104

29. Panis C, Herrera A, Aranome AMF, et al. Clinical insights from adiponectin analysis in breast cancer patients reveal its anti-inflammatory properties in non-obese women. Mol Cell Endocrinol. 2014;382:190-196. doi:10.1016/j.mce.2013.09.030

30. Vehmanen L, Saarto T, Blomqvist C, Taskinen MR, Elomaa I. Tamoxifen treatment reverses the adverse effects of chemotherapy-induced ovarian failure on serum lipids. Br J Cancer. 2004;91:476-481. doi:10.1038/sj. bjc.6601979

31. Panis C, Binato R, Correa S, et al. Short infusion of paclitaxel imbalances plasmatic lipid metabolism and correlates with cardiac markers of acute damage in patients with breast cancer. Cancer Chemother Pharmacol. 2017;80:469-478. doi:10.1007/s00280-0173384-8

32. Hozumi Y, Suemasu K, Takei H, et al. The effect of exemestane, anastrozole, and tamoxifen on lipid profiles in Japanese postmenopausal early breast cancer patients: final results of National Surgical Adjuvant Study BC 04, the TEAM Japan sub-study. Ann Oncol. 2011;22:1777-1782. doi:10.1093/annonc/mdq707

33. Parhofer KG. New approaches to address dyslipidemia. Curr Opin Lipidol. 2017;28:452-457. doi:10.1097/MOL.0000000000000456

34. Wu Y, Si R, Tang H, et al. Cholesterol reduces the sensitivity to platinum-based chemotherapy via upregulating ABCG2 in lung adenocarcinoma. Biochem Biophys Res Commun. 2015;457:614-620. doi:10.1016/j.bbrc.2015.01.035

35. Matikas A, Foukakis T, Bergh J. Dose intense, dose dense and tailored dose adjuvant chemotherapy for early breast cancer: an evolution of concepts. Acta Oncol. 2017;56:1143-1151. doi:10.10 80/0284186X.2017.1329593 
36. Foukakis T, von Minckwitz G, Bengtsson NO, et al.; Swedish Breast Cancer Group tGBG, the Austrian B and Colorectal Cancer Study G. Effect of tailored dose-dense chemotherapy vs standard 3-weekly adjuvant chemotherapy on recurrence-free survival among women with high-risk early breast cancer: a randomized clinical trial. JAMA. 2016;316:1888-1896. doi:10.1001/jama.2016.15865

37. Bonilla L, Ben-Aharon I, Vidal L, Gafter-Gvili A, Leibovici L, Stemmer SM. Dose-dense chemotherapy in nonmetastatic breast cancer: a systematic review and meta-analysis of randomized controlled trials. J Natl Cancer Inst. 2010;102:1845-1854. doi:10.1093/ jnci/djq409

38. Delarue R, Tilly H, Mounier N, et al. Dose-dense rituximab-CHOP compared with standard rituximab-CHOP in elderly patients with diffuse large B-cell lymphoma (the LNH03-6B study): a randomised Phase 3 trial. Lancet Oncol. 2013;14:525-533. doi:10.1016/S1470-2045(13)70122-0

39. Cheng-Zhi Xu R-JS, Dong C, Yi-Yuan S, Qing-Wei W, Tao W, PeiHua W. Potential biomarkers for paclitaxel sensitivity in hypopharynx cancer cell.pdf. Int J Clin Exp Pathol. 2013;6:2745-2756.

40. Turner N, Biganzoli L, Di Leo A. Continued value of adjuvant anthracyclines as treatment for early breast cancer. Lancet Oncol. 2015;16:e362-e369. doi:10.1016/S1470-2045(15)00079-0

41. Gianni L, Norton L, Wolmark N, Suter TM, Bonadonna G, Hortobagyi GN. Role of anthracyclines in the treatment of early breast cancer. J Clin Oncol. 2009;27:4798-4808. doi:10.1200/ JCO.2008.21.4791

42. Tan QW, Luo T, Zheng H, et al. Weekly taxane-anthracycline combination regimen versus tri-weekly anthracycline-based regimen for the treatment of locally advanced breast cancer: a randomized controlled trial. Chin J Cancer. 2017;36:27. doi:10.1186/s40880-0170196-5
43. Mamounas EP, Bryant J, Lembersky B, et al. Paclitaxel after doxorubicin plus cyclophosphamide as adjuvant chemotherapy for node-positive breast cancer: results from NSABP B-28. J Clin Oncol. 2005;23:3686-3696. doi:10.1200/JCO.2005.10.517

44. Mackey JR, Martin M, Pienkowski T, et al. Adjuvant docetaxel, doxorubicin, and cyclophosphamide in node-positive breast cancer: 10-year follow-up of the phase 3 randomised BCIRG 001 trial. Lancet Oncol. 2013;14:72-80.

45. Kalabova H, Melichar B, Ungermann L, et al. Intima-media thickness, myocardial perfusion and laboratory risk factors of atherosclerosis in patients with breast cancer treated with anthracycline-based chemotherapy. Med Oncol. 2011;28:1281-1287. doi:10.1007/s12032-010-9593-1

46. Hiona A, Lee AS, Nagendran J, et al. Pretreatment with angiotensin-converting enzyme inhibitor improves doxorubicin-induced cardiomyopathy via preservation of mitochondrial function. J Thorac Cardiovasc Surg. 2011;142:396-403 e393. doi:10.1016/j.jtcvs.2010.07.097

47. Sharma M, Tuaine J, McLaren B, et al. Chemotherapy agents alter plasma lipids in breast cancer patients and show differential effects on lipid metabolism genes in liver cells. PLoS One. 2016;11: e0148049. doi:10.1371/journal.pone.0148049

48. Jenei Z, Bardi E, Magyar MT, Horvath A, Paragh G, Kiss C. Anthracycline causes impaired vascular endothelial function and aortic stiffness in long term survivors of childhood cancer. Pathol Oncol Res. 2013;19:375-383. doi:10.1007/s12253-012-9589-6

49. Kim SB, Kok YT, Thuan TV, Chao TY, Shen ZZ. Safety results of docetaxel-(taxotere (R))-based chemotherapy in early breast cancer patients of asia-pacific region: asia-pacific breast initiative II. J Breast Cancer. 2015;18:356-364. doi:10.4048/jbc.2015.18.4.356

\section{Publish your work in this journal}

Cancer Management and Research is an international, peer-reviewed open access journal focusing on cancer research and the optimal use of preventative and integrated treatment interventions to achieve improved outcomes, enhanced survival and quality of life for the cancer patient.
The manuscript management system is completely online and includes a very quick and fair peer-review system, which is all easy to use. Visit http://www.dovepress.com/testimonials.php to read real quotes from published authors. 